\title{
Associated factors for depressive disorder in patients with end-stage renal disease treated with continuous ambulatory peritoneal dialysis
}

This article was published in the following Dove Medical Press journal: Therapeutics and Clinical Risk Management

\author{
Patrinee Traisathit ${ }^{\prime}$ \\ Kasiramart Moolkham² \\ Narong Maneeton ${ }^{2}$ \\ Natthapat Thongsak' \\ Benchalak Maneeton ${ }^{2}$ \\ 'Department of Statistics, Faculty \\ of Science, Chiang Mai University, \\ Chiang Mai, Thailand; ${ }^{2}$ Department of \\ Psychiatry, Faculty of Medicine, Chiang \\ Mai University, Chiang Mai, Thailand
}

Correspondence: Benchalak Maneeton Department of Psychiatry, Faculty of Medicine, Chiang Mai University, I 10 Intawaroros Road, Sriphum, Amphur Muang, Chiang Mai 50200, Thailand Tel +66 53935422

Fax +6653935426

Email benchalak.maneeton@cmu.ac.th
Background: The aim of this study was to primarily determine factors associated with the depressive disorders in continuous ambulatory peritoneal dialysis (CAPD).

Methods: CAPD patients were recruited from the chronic kidney disease and CAPD Clinic of University Hospital. The stable CAPD patients for at least 3 months were included in the study. Sociodemographic data, renal conditions, and depressive disorder were evaluated. In addition to determining prevalence rate of depressive disorders, identification of factors associated with depressive disorders in CAPD patients were analyzed by using the multivariable logistic regression analysis with backward elimination procedure.

Results: The eligible participants were 108 patients. The study found that $11 \%$ of CAPD patients were diagnosed with depressive disorders including, minor depressive, dysthymic, and major depressive disorders. Additionally, the depressive disorders were associated with the duration between the diagnosis date of the end-stage renal disease (ESRD) and the initial treatment date $(P=0.043)$. Accordingly, the ESRD patients diagnosed in $<12$ months had 3.57-fold higher risk of depressive disorders than the patients diagnosed after a long time.

Conclusion: The rate of prevalence for depressive disorder is high in the CAPD patients. Additionally, the results of this study have shown the relationship between depressive disorder and time for diagnosis of ESRD. Specifically, the risk of depressive disorder increases when patients have a shorter duration between the dates of ESRD diagnosis and initial treatment. In addition to closed monitoring for those patients, the psychiatrists should be consulted for evaluation and treatment of depressive disorders for the suspected high risk patients.

Keywords: peritoneal dialysis, depressive disorder, end-stage renal disease, cross-sectional study, prevalence of depression, chronic kidney disease, psychosocial factor, the patient health questionnaire

\section{Background}

Depressive disorder is a common illness worldwide with $>300$ million people affected and can become a serious health issue leading to suicide; nearly 800,000 people die annually due to suicide. ${ }^{1}$ Additionally, patients with chronic diseases having limitations in their daily life may increase the risk of depressive disorder. ${ }^{2}$ The previous evidence indicates that the prevalence of depressive disorder is 1.44 and 2.25 times higher for those patients reporting one and two or more chronic diseases, respectively, than those with none. ${ }^{3}$

Chronic kidney disease (CKD) is a progressive loss in kidney function over a period of months or years. The consequence of undetected CKD is the risk of developing progressive loss of kidney function that can lead to kidney failure, also called end-stage renal disease (ESRD). ${ }^{4}$ The ESRD population has grown substantially and is a major 
burden on public health. ${ }^{5}$ Renal replacement therapies with dialysis and kidney transplants are the only means of sustaining life for patients with ESRD. However, the number of donor kidneys is limited and transplants may fail, demonstrating a limitation of this approach. The two principal modes of dialysis for patients with ESRD are hemodialysis and continuous ambulatory peritoneal dialysis (CAPD). ${ }^{6}$ Consequently, those patients may have a higher risk of psychiatric illness, including depressive disorder.

In general, the prevalence rate of depressive disorder in the CAPD patients is high. For instance, the study among the CAPD patients in Turkey found that the prevalence rate was $62.5 \%$. ${ }^{7}$ Similarly, the prevalence rate of depressive disorder in Asian patients with CAPD was also high: $53.8 \%$ in Korea, ${ }^{8}$ $34.0 \%$ in China, ${ }^{9}$ and $42.0 \%$ for female, ${ }^{10}$ and $47.3 \%$ for outpatient patients ${ }^{11}$ in Thailand.

Previous studies found that the occurrence of depressive disorder in ESRD patients was associated with baseline characteristics such as age, sex, occupation, social support, fatigue, malnutrition, and comorbidity. 7,9,12

In addition, depressive disorder in ESRD patients was associated with treatment-related variables such as having either hemodialysis or peritoneal dialysis (PD), caregiver, level of activity in their daily lives, inflammation, long PD duration, interdialytic urine volume, and residual renal function. ${ }^{7,9,12,13}$ Nevertheless, these studies have not included a number of other variables that may be associated with depressive disorder in ESRD patients treated by CAPD such as having financial problems, type of medical bill payment, time since diagnosis, number of cycles per day, and succumbing to infection from treatment.

The aim of our study was to identify factors linked with depressive disorder in CAPD patients. Additionally, its prevalent rate was also determined.

\section{Methods}

This was a cross-sectional study in CAPD patients receiving services at the CKD and CAPD Clinic of University Hospital, a tertiary-care setting in our country. The study was conducted from June to September 2010. The CAPD patients aged $\geq 18$ years and capable of verbal communication were included in the study. Since onset of adjustment disorder usually occurs within 3 months of stressor, only stable CAPD patients for at least 3 months were included to determine whether they were depressive disorders. Eligible patients were provided details about the assessment procedure (Figure 1). The informed consent was given after the study details had been fully explained. The patients completed all the questionnaires in a single visit. The present study was approved and monitored by the Ethics Committee of Faculty of Medicine, Chiang Mai University. All participants gave written informed consent. Present study was also conducted in accordance with the Declaration of Helsinki.

\section{Assessment}

Sociodemographic data: All baseline characteristics of CAPD patients were evaluated. General sociodemographic data such as gender, age, educational level, marriage status, having attendant, occupation, income, type of medical bills payment, financial problems, future treatment plan, having an assistant in daily life, having an assistant to change solutions, and a family history of depressive disorder were assessed.

Renal factors: The ESRD was defined as an eGFR of $<15 \mathrm{~mL} / \mathrm{min} / 1.73 \mathrm{~m}^{2} .{ }^{14}$ Medical illness aspects such as time since diagnosis, treatment duration, codisease(s), biological marker level in the blood (blood urea nitrogen, creatinine, potassium, hemoglobin, hematocrit), number of treatments measured in cycle per day, and having succumbed to infection from treatment (peritonitis and infection exit side) were recorded.

Depressive disorder: The Patient Health Questionnaire (PHQ-9), ${ }^{15}$ a reliable and validated measure, was used to assess depressive disorder in this study. The PHQ is a ninequestionnaire screen for the presence and severity of depressive disorder, which makes a depressive disorder diagnosis according to the Diagnostic and Statistical Manual of Mental Disorders-IV-Text Revision criteria. The total of all nine responses from the PHQ-9 aim to predict the presence and severity of depressive disorder. Each item in the PHQ-9 ranges from 0 (not at all), to 1 (several days), 2 (more than half of the days), and 3 (nearly every day), of which the total summed scores range from 0 to 27 . The cutoff scores for the diagnosis of depressive disorders, including minor depressive, dysthymic and major depressive disorders, is $\geq 10$.

\section{Statistical analyses}

Baseline characteristics were presented as mean and SD for continuous variables and counts and percentages for categorical variables. Associated factors taken into consideration were sociodemographic data and renal factors. PHQ-9 scores were used to identify depressive disorders in CAPD patients. Patients who had PHQ-9 scores $\geq 10$ were diagnosed with depressive disorder. Associated factors of depressive disorder were assessed by using logistic regression. Factors associated with the risk of depressive disorder with a $P$-value $<0.25$ in the univariable analysis were included in the multivariable analysis with backward elimination procedure. All analyses were performed using STATA, version 12. 


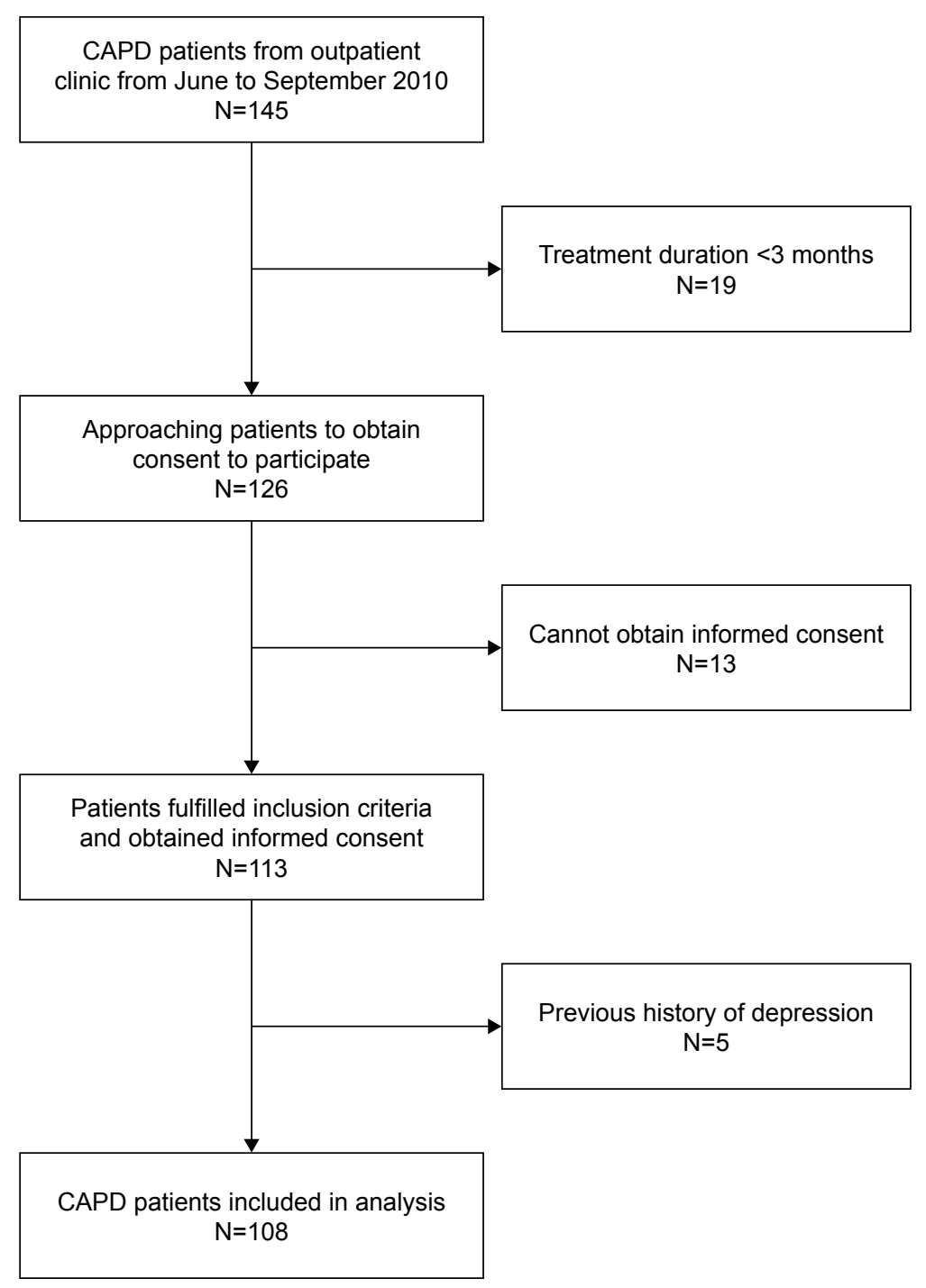

Figure I Flow diagram for the study enrollment and completion for CAPD patients. Abbreviation: CAPD, continuous ambulatory peritoneal dialysis.

\section{Result}

A total of 113 adult patients with ESRD with not $<3$ months of treatment duration were screened for enrollment. Patients who had a history of depressive disorder before starting the CAPD ( $n=5)$ were excluded from the study, which left a sample of 108 patients (Figure 1). Based on the PHQ-9, the prevalence rate of depressive disorders in CAPD patients was $11.11 \%(12 / 108)$. The eligible participants included 56 male (52\%) and 52 (48\%) female patients with a mean age (SD) of 54.80 (11.12) and 51.84 (11.10) years, respectively (Table 1). Most of the participants had 0-6 years of education and were married. Almost all participants (98\%) had attendant. Unfortunately, the majority of them $(60 \%)$ were unemployed; therefore, the average income was low: $80 \%$ of CAPD patients had an annual income of $\leq$ US $\$ 1,850$, only
$15 \%$ of their bills payment was reimbursement, as well as $48 \%$ of them had financial problems. Mean (SD) duration of time since diagnosis ESRD and treatment duration (CAPD) was 29.0 (44.3) and 13.4 (7.9) months, respectively. Most of the CAPD patients had comorbidities, including hypertension, diabetes mellitus, and heart disease. Although most of them had a care provider helping them for daily CAPD, they also performed the self-care dialysis. Blood tests of patients and dialysis cycles per day were also shown in Table 1. After dialysis, some of patients succumbed to infection. Even though the CAPD patients had peritonitis or infection at exit side, most of CAPD patients planned to maintenance the dialysis.

Table 2 shows the univariable logistic regression analysis of associated factors for depressive disorders in the ESRD patients treated with the CAPD. Patients diagnosed with 
Table I Demographics and clinical characteristics of 108 patients with end-stage renal disease treated with continuous ambulatory peritoneal dialysis

\begin{tabular}{|c|c|c|c|}
\hline \multirow[t]{2}{*}{ Demographics and clinical data } & \multicolumn{3}{|c|}{ n (\%) or mean (SD) } \\
\hline & All $(n=108)$ & With depression $(n=\mid 2)$ & Without depression $(n=96)$ \\
\hline Male & $56(52 \%)$ & $9(75 \%)$ & 47 (49\%) \\
\hline Age (years) & $53.4(11.2)$ & $51.2(13.8)$ & $53.7(10.8)$ \\
\hline \multicolumn{4}{|l|}{ Education level } \\
\hline Primary school or lower & $83(77 \%)$ & $9(75 \%)$ & $74(77 \%)$ \\
\hline Higher than primary school & $25(23 \%)$ & $3(25 \%)$ & $22(23 \%)$ \\
\hline \multicolumn{4}{|l|}{ Marriage status } \\
\hline Single/divorced/separated & $21(19 \%)$ & $3(25 \%)$ & $18(19 \%)$ \\
\hline Married/living together & $87(81 \%)$ & $9(75 \%)$ & $78(81 \%)$ \\
\hline Having attendant: yes & 106 (98\%) & $12(100 \%)$ & 106 (98\%) \\
\hline \multicolumn{4}{|l|}{ Occupation } \\
\hline Unemployed & $65(60 \%)$ & $7(58 \%)$ & $58(60 \%)$ \\
\hline Employed & $43(40 \%)$ & $5(42 \%)$ & $38(40 \%)$ \\
\hline \multicolumn{4}{|l|}{ Annual income (US dollar) } \\
\hline$<1,850$ & $87(80 \%)$ & $10(83 \%)$ & 77 (80\%) \\
\hline$\geq 1,850$ & $21(20 \%)$ & $2(17 \%)$ & $19(20 \%)$ \\
\hline \multicolumn{4}{|l|}{ Type of medical bills payment } \\
\hline Reimbursement & $16(15 \%)$ & $2(17 \%)$ & $14(15 \%)$ \\
\hline Others & $92(85 \%)$ & $10(83 \%)$ & $82(85 \%)$ \\
\hline Having financial problem: yes & $51(48 \%)$ & $8(67 \%)$ & $43(45 \%)$ \\
\hline Time since diagnosis (months) & $29.0(44.3)$ & $23.0(34.7)$ & $29.7(45.4)$ \\
\hline Treatment duration (months) & $13.4(7.9)$ & $15.7(7.9)$ & $13.2(7.9)$ \\
\hline Have a codisease & $95(88 \%)$ & II (92\%) & $84(87 \%)$ \\
\hline \multicolumn{4}{|l|}{ Comorbidity } \\
\hline Diabetes mellitus & $39(36 \%)$ & $5(42 \%)$ & $34(35 \%)$ \\
\hline Heart disease & $16(15 \%)$ & $2(17 \%)$ & $14(15 \%)$ \\
\hline Hypertension & $72(67 \%)$ & $9(75 \%)$ & $63(66 \%)$ \\
\hline Other & $50(46 \%)$ & $8(67 \%)$ & 42 (44\%) \\
\hline \multicolumn{4}{|l|}{ Biological marker levels in the blood" } \\
\hline BUN (mg/dL) & $47.1(15.5)$ & $46.5(12.9)$ & $47.2(15.9)$ \\
\hline Creatinine $(\mathrm{mg} / \mathrm{dL})$ & $10.6(3.6)$ & $9.6(1.9)$ & $10.7(3.8)$ \\
\hline $\mathrm{K}(\mathrm{mEq} / \mathrm{dL})$ & $3.7(0.8)$ & $3.5(0.9)$ & $3.8(0.8)$ \\
\hline Hemoglobin (gm\%) & $11.3(1.6)$ & $11.0(1.4)$ & II.4 (I.6) \\
\hline Hematocrit (\%) & $34.3(4.8)$ & $34.0(4.6)$ & $34.3(4.8)$ \\
\hline \multicolumn{4}{|l|}{ Number of treatment (cycles per day) } \\
\hline $\mathrm{I}-3$ & $29(27 \%)$ & $\mathrm{I}(8 \%)$ & $28(29 \%)$ \\
\hline$\geq 4$ & $79(73 \%)$ & II (92\%) & $68(71 \%)$ \\
\hline Succumbed to infection from treatment & $37(34 \%)$ & $6(50 \%)$ & $31(32 \%)$ \\
\hline \multicolumn{4}{|l|}{ Infection from treatment } \\
\hline Peritonitis & $25(68 \%)$ & $5(83 \%)$ & $20(64 \%)$ \\
\hline Infection exit side & $16(43 \%)$ & $2(33 \%)$ & 14 (45\%) \\
\hline Have an assistant in daily life & $15(14 \%)$ & $\mathrm{I}(8 \%)$ & $14(15 \%)$ \\
\hline Change solution by themselves & $93(86 \%)$ & II (92\%) & $82(85 \%)$ \\
\hline \multicolumn{4}{|l|}{ Plan for treatment in the future" } \\
\hline Maintenance dialysis & 106 (99\%) & $12(100 \%)$ & 94 (99\%) \\
\hline Renal transplantation & $\mathrm{I}(\mathrm{l} \%)$ & $0(0 \%)$ & $\mathrm{I}(\mathrm{I} \%)$ \\
\hline
\end{tabular}

Note: "One patient did not answer the questions about Plan for treatment in the future.

Abbreviation: BUN, blood urea nitrogen. 
Table 2 Univariable logistic regression analysis of potential risk factors for depression in patients with end-stage renal disease treated with continuous ambulatory peritoneal dialysis

\begin{tabular}{|c|c|c|c|c|}
\hline \multirow[t]{2}{*}{ Variables } & \multirow[t]{2}{*}{ n/N (\%) } & \multicolumn{3}{|c|}{ Univariable analysis } \\
\hline & & OR & $95 \% \mathrm{Cl}$ & $P$-value ${ }^{a}$ \\
\hline \multicolumn{5}{|l|}{ Gender } \\
\hline Male & $9 / 56(16 \%)$ & 3.13 & $0.80-12.26$ & 0.102 \\
\hline Female & $3 / 52(6 \%)$ & 1.00 & - & - \\
\hline \multicolumn{5}{|l|}{ Age (years) } \\
\hline$<55$ & $5 / 58(9 \%)$ & 1.00 & - & - \\
\hline$\geq 55$ & $7 / 50(4 \%)$ & 1.73 & $0.5 I-5.82$ & 0.379 \\
\hline \multicolumn{5}{|l|}{ Education level } \\
\hline Primary school or lower & $9 / 83(11 \%)$ & 1.00 & - & - \\
\hline Higher than primary school & $3 / 25(12 \%)$ & 1.12 & $0.28-4.50$ & 0.872 \\
\hline \multicolumn{5}{|l|}{ Marriage status } \\
\hline Single/divorced/separated & $3 / 21$ (14\%) & 1.44 & $0.35-5.88$ & 0.608 \\
\hline Married/living together & $9 / 87(10 \%)$ & 1.00 & - & - \\
\hline \multicolumn{5}{|l|}{ Occupation } \\
\hline Unemployed & $7 / 65$ (11\%) & 1.00 & - & - \\
\hline Employed & $5 / 43(12 \%)$ & 1.09 & $0.32-3.69$ & 0.889 \\
\hline \multicolumn{5}{|l|}{ Annual income (US\$) } \\
\hline$<\mathrm{I}, 850$ & I0/87 (1 I\%) & 1.23 & $0.25-6.11$ & 0.797 \\
\hline$\geq 1,850$ & $2 / 21$ (10\%) & 1.00 & - & - \\
\hline \multicolumn{5}{|l|}{ Type of medical bill payment } \\
\hline Reimbursement & $2 / 16(13 \%)$ & 1.17 & $0.23-5.92$ & 0.848 \\
\hline Others & 10/92 (11\%) & 1.00 & - & - \\
\hline \multicolumn{5}{|l|}{ Have financial problems } \\
\hline No & $4 / 57(7 \%)$ & 1.00 & - & - \\
\hline Yes & $8 / 51(16 \%)$ & 2.47 & $0.67-8.74$ & 0.162 \\
\hline \multicolumn{5}{|l|}{ Time since diagnosis (months) } \\
\hline$<12$ & $6 / 27$ (19\%) & 3.57 & $1.04-12.23$ & $0.043^{*}$ \\
\hline$\geq 12$ & $6 / 81(4 \%)$ & 1.00 & - & - \\
\hline \multicolumn{5}{|l|}{ Treatment duration (months) } \\
\hline$<12$ & $2 / 39(5 \%)$ & 1.00 & - & - \\
\hline$\geq 12$ & $10 / 69(14 \%)$ & 3.14 & $0.65-15.11$ & 0.154 \\
\hline \multicolumn{5}{|l|}{ Having a codisease } \\
\hline No & $1 / 13(8 \%)$ & 1.00 & - & - \\
\hline Yes & II/95 (I2\%) & 1.57 & $0.19-13.28$ & 0.678 \\
\hline \multicolumn{5}{|l|}{ Biological marker levels in blood } \\
\hline \multicolumn{5}{|l|}{ BUN (mg/dL) } \\
\hline$\leq 20$ & $0 / 2(0 \%)$ & & & \\
\hline$>20$ & $12 / 105(11 \%)$ & & & \\
\hline \multicolumn{5}{|l|}{ Creatinine $(\mathrm{mg} / \mathrm{dL})$} \\
\hline$\leq 1.21$ & $0 / 0(0 \%)$ & & & \\
\hline$>1.21$ & $12 / 107(\mid 1 \%)$ & & & \\
\hline \multicolumn{5}{|l|}{$\mathrm{K}(\mathrm{mEq} / \mathrm{dL})$} \\
\hline$\leq 5.2$ & II/IOI (II\%) & 1.00 & - & - \\
\hline$>5.2$ & I/6 (I7\%) & 1.64 & $0.17-15.32$ & 0.666 \\
\hline
\end{tabular}


Table 2 (Continued)

\begin{tabular}{|c|c|c|c|c|}
\hline \multirow[t]{2}{*}{ Variables } & \multirow[t]{2}{*}{ n/N (\%) } & \multicolumn{3}{|c|}{ Univariable analysis } \\
\hline & & OR & $95 \% \mathrm{Cl}$ & $P$-value ${ }^{\text {a }}$ \\
\hline \multicolumn{5}{|c|}{ Hemoglobin (gm\%) } \\
\hline$\leq 12.75$ & II/88 (13\%) & 2.57 & $0.3 \mathrm{I}-2 \mathrm{I} .23$ & 0.380 \\
\hline$>12.75$ & $1 / 19(5 \%)$ & 1.00 & - & - \\
\hline \multicolumn{5}{|c|}{ Hematocrit (\%) } \\
\hline$\leq 36.85$ & $9 / 77$ (I2\%) & 1.19 & $0.30-4.74$ & 0.804 \\
\hline$>36.85$ & $3 / 30(10 \%)$ & 1.00 & - & - \\
\hline \multicolumn{5}{|c|}{ Number of treatment cycles per day } \\
\hline $1-3$ & $\mathrm{I} / 29(3 \%)$ & 1.00 & - & - \\
\hline$\geq 4$ & II/79 (14\%) & 4.53 & $0.56-36.76$ & 0.157 \\
\hline \multicolumn{5}{|c|}{ Succumbed to infection from treatment } \\
\hline No & $6 / 7 \mid(8 \%)$ & 1.00 & - & - \\
\hline Yes & $6 / 37(16 \%)$ & 2.10 & $0.63-7.03$ & 0.230 \\
\hline \multicolumn{5}{|c|}{ Have an assistant in daily life } \\
\hline No & II/93 (12\%) & 1.88 & $0.22-15.7 \mid$ & 0.561 \\
\hline Yes & $1 / 15(7 \%)$ & 1.00 & - & - \\
\hline \multicolumn{5}{|c|}{ Change solution by themselves } \\
\hline No & $1 / 15(7 \%)$ & 1.00 & - & - \\
\hline Yes & $11 / 93$ (12\%) & 1.88 & $0.22-|5.7|$ & 0.561 \\
\hline
\end{tabular}

Notes: aP-values from logistic regression. *Significantly different.

Abbreviation: BUN, blood urea nitrogen.

ESRD in $<12$ months $(\mathrm{OR}=3.57 ; 95 \% \mathrm{CI}=1.04-12.23$; $P=0.043$ ) had a significantly higher risk of depressive disorders. In addition, this factor was confirmed to be associated with a high risk of depressive disorder by using the multivariable analysis $(\mathrm{OR}=3.57 ; 95 \% \mathrm{CI}=1.04-12.23 ; P=0.043$ ) (Table 3).

\section{Discussion}

From the study, $11 \%$ of CAPD patients were diagnosed with depressive disorders. The depressive disorders were associated with the duration between the diagnosis date of ESRD and the initial treatment date $(P=0.043)$. Comparison with longer ones, the risk of depressive disorders in such patients increased to 3.57 times when the duration was $<12$ months.

Previous studies found that the prevalence of depressive disorder in CAPD patients was as high as $34 \%-62.5 \%,{ }^{7-11}$ while the prevalent rate in the present study was only $11 \%$. The difference of such outcomes could result from using the different measures in evaluation of depressive disorder. To identify depressive disorders, the present study used the PHQ-9, which has the potential of being a dual-purpose instrument that can establish depressive disorder diagnoses as well as grade depressive symptom severity. ${ }^{15}$ However, while rest of studies applied the different measures, including

Table 3 Multivariable logistic regression analysis of potential risk factors for depression in patients with end-stage renal disease treated with continuous ambulatory peritoneal dialysis

\begin{tabular}{|l|l|l|l|l|l|}
\hline Variables & Adjust OR $(95 \%$ CI) & Coefficient & SE & $Z$ & $P_{\text {-value }}$ \\
\hline Male & $2.23(0.52-9.62)$ & 0.80 & 0.746 & 1.08 & 0.282 \\
\hline Having financial problems & $2.72(0.69-10.67)$ & 1.00 & 0.697 & 1.44 & $0.15 \mathrm{I}$ \\
\hline Time since diagnosis: $<12$ months & $3.57(1.04-12.23)$ & 1.27 & 0.628 & 2.03 & 0.043 \\
\hline Treatment duration: $\leq 12$ months & $3.89(0.77-19.72)$ & 1.36 & 0.828 & 1.64 & 0.101 \\
\hline Number of treatment: $\leq 4$ cycles per day & $6.39(0.74-55.25)$ & 1.85 & 1.101 & 1.68 & 0.092 \\
\hline Succumbed to infection from peritoneal dialysis & $1.36(0.32-5.83)$ & 0.31 & 0.742 & 0.42 & 0.677 \\
\hline Constant & & -2.53 & 0.424 & -5.95 & $<0.001$ \\
\hline
\end{tabular}

Note: a ${ }^{P}$-values from multivariable logistic regression.

Abbreviation: SE, standard error. 
the Beck Depression Inventory (BDI) ${ }^{7,8}$ and the BDI-II, ${ }^{9}$ our study using PHQ-9 with a cutoff score of 10 points (which has often been recommended) had a sensitivity of $88 \%$ and a specificity of $88 \% .{ }^{15}$ However, further studies may verify the present outcomes.

Based on previous studies, the prevalence of depression in CAPD and hemodialysis (HD) patients varied. Several previous evidence found that prevalent rate of depression between CAPD and hemodialysis (HD) was comparable. ${ }^{16-18}$ Unfortunately, a previous study reported the higher prevalence of depression, measured by the Hospital Anxiety and Depression Scale, in CAPD patients than that of HD patients; ${ }^{19}$ the rest illustrated the greater prevalence of depression, measured by the BDI, in HD group. ${ }^{20-22}$ Those varied outcomes may rely on the sociodemographic and clinical basic characteristics of individually included participants in each study. Additionally, the various measures were applied across those studies that may also affect those various outcomes.

Our study found that only the duration between diagnosis of ESRD and initial treatment date was associated with depressive disorder, while the previous studies found that sex (female), age, occupation, and having a codisease were associated with depressive disorder. ${ }^{12,17}$ The different outcomes may relate to the cultural differences.

Based on the present finding, up to $88 \%$ patients had codisease, including diabetes mellitus, cardiac disease, hypertension, and others, which had negative impact on loss of physical wellbeing, possibly leading to increase prevalence of depression. ${ }^{23,24}$ Additionally, recent evidence found the biological contributors to depression, including inflammatory cytokines, deregulation of the hypothalamus-pituitary-adrenal axis, disturbance in glucose-insulin homeostasis, and oxidative stress in CKD patients. ${ }^{25}$ Recently, a relationship was also found between depression and presence of inflammation parameters in CAPD patients. ${ }^{22}$ According to biological factors, the ESRD patients with CAPD have high risk of depression.

Several psychosocial factors are able to contribute to the development of depression in any point of CKD stages. ${ }^{25}$ Psychosocial factors are mainly related to depression, including having loss of a sense of accomplishment, self-esteem, and identity due to change in their job, physical status, lifestyle, and social roles. ${ }^{25,26}$ After diagnosed in ESRD, those patients often encounter variety of detrimental problems in the physical health, identity, family, lifestyles, relationships, employments, disease prognosis and treatment outcome, and health care system, ${ }^{25,27}$ causing stress, anxiety, and ultimately leading to depressive disorder. ${ }^{26}$ Then those patients possibly better adjust to those difficulties leading to reduce the prevalence of depressive disorder in later. ${ }^{27}$ Thus, the early screening and treatment of depressive disorder or depressive symptoms for those patients with the first diagnosis of ESRD are necessary.

\section{Limitations}

There are some limitations in this study. First, since this is a cross-sectional study that enrolled a relatively small number of adult patients with ESRD treated by CAPD, there is less probability that it can identify more risk factors.

Second, since the depressive disorders in this study were only identified by using the PHQ-9 questionnaire instead of the clinician-rated measures, validity of diagnosis may be inconsistent. Third, other factors that could have been associated with depressive disorder, including the inflammatory markers or sleep disorders were not included in this analysis.

\section{Conclusion}

The results of this study have shown the relationship between depressive disorder and time since diagnosis in CAPD patients. Specifically, we found that the risk of depressive disorder was high when patients had a short duration between ESRD diagnosis date and initial treatment date. Hence, we should observe these patients closely and possibly ask for cooperation from psychiatrists to treat them. However, further well-designed studies should be performed to warrant these finding.

\section{Acknowledgment}

This work was supported by the Faculty of Medicine and CMU Mid-Career Researcher Program, Chiang Mai University, Thailand.

\section{Author contributions}

All authors contributed to data analysis, drafting or revising the article, gave final approval of the version to be published, and agree to be accountable for all aspects of the work.

\section{Disclosure}

This study was not supported by the industry. BM has received honoraria and/or travel reimbursement from Lundbeck, Servier, and Pfizer. NM has received travel reimbursement from Lundbeck and Pfizer. PT, KM, and NT report no conflicts of interest in this work.

\section{References}

1. World Health Organization [homepage on the Internet]. Depression: Fact Sheet; 2017. Available from: http://www.who.int/mediacentre/factsheets/ fs369/en/. Accessed March 15, 2017. 
2. Katon WJ. Epidemiology and treatment of depression in patients with chronic medical illness. Dialogues Clin Neurosci. 2011;13(1):7-23.

3. Boing AF, Melo GR, Boing AC, Moretti-Pires RO, Peres KG, Peres MA. Association between depression and chronic diseases: results from a population-based study. Rev Saude Publica. 2012;46(4):617-623. Portuguese.

4. World Kidney Day [homepage on the Internet]. Chronic kidney disease; 2017. Available from: http://www.worldkidneyday.org/faqs/chronickidney-disease/. Accessed March 15, 2017.

5. Xue JL, Ma JZ, Louis TA, Collins AJ. Forecast of the number of patients with end-stage renal disease in the United States to the year 2010. J Am Soc Nephrol. 2001;12(12):2753-2758.

6. Vale L, Cody J, Wallace S, et al. Continuous ambulatory peritoneal dialysis (CAPD) versus Hospital or home haemodialysis for endstage renal disease in adults. Cochrane Database Syst Rev. 2004;(4): CD003963.

7. Guney I, Solak Y, Atalay H, et al. Comparison of effects of automated peritoneal dialysis and continuous ambulatory peritoneal dialysis on health-related quality of life, sleep quality, and depression. Hemodial Int. 2010;14(4):515-522.

8. Ko GJ, Kim MG, Yu YM, Jo SK, Cho WY, Kim HK. Association between depression symptoms with inflammation and cardiovascular risk factors in patients undergoing peritoneal dialysis. Nephron Clin Pract. 2010;116(1):c29-c35.

9. Lin J, Guo Q, Ye X, et al. The effect of social support and coping style on depression in patients with continuous ambulatory peritoneal dialysis in southern China. Int Urol Nephrol. 2013;45(2):527-535.

10. Prapaiwong P, Sriyuktasuth A, Ayuthya SKN, Vongsirimas N. Factors influencing quality of life in women receiving continuous ambulatory peritoneal dialysis. Princess Naradhiwas Univ J. 2015;7:37-46.

11. Artiwitchayanon A, Keeratiyutawong P, Duangpaeng S. Predictors of self-management in patients with chronic kidney disease undergoing continuous ambulatory peritoneal dialysis. Ramathibodi Nurs J. 2015; 21(2):172-185.

12. Sindhu S, Varitsakul R, Sriyuktasuth A. Factors associated with depression in elderly peritoneal dialysis patients. J Nurs Sci. 2011;29:84-91.

13. Chilcot J, Wellsted D, Vilar E, Farrington K. An association between residual renal function and depression symptoms in haemodialysis patients. Nephron Clin Pract. 2009;113(2):c117-c124.
14. Agarwal R. Defining end-stage renal disease in clinical trials: a framework for adjudication. Nephrol Dial Transplant. 2016;31(6):864-867.

15. Kroenke K, Spitzer RL, Williams JB. The PHQ-9: validity of a brief depression severity measure. J Gen Intern Med. 2001;16(9):606-613.

16. Losso RL, Minhoto GR, Riella MC. Sleep disorders in patients with end-stage renal disease undergoing dialysis: comparison between hemodialysis, continuous ambulatory peritoneal dialysis and automated peritoneal dialysis. Int Urol Nephrol. 2015;47(2):369-375.

17. Sithinamsuwan $P$, Niyasom S, Nidhinandana S, Supasyndh O. Dementia and depression in end stage renal disease: comparison between hemodialysis and continuous ambulatory peritoneal dialysis. $J$ Med Assoc Thai. 2005;88(Suppl 3):S141-S147.

18. Iordanidis $\mathrm{P}$, Alivanis $\mathrm{P}$, Iakovidis $\mathrm{A}$, et al. Psychiatric and psychosocial status of elderly patients undergoing dialysis. Perit Dial Int. 1993; 13(Suppl 2):S192-S195.

19. Griva K, Kang AW, Yu ZL, et al. Quality of life and emotional distress between patients on peritoneal dialysis versus community-based hemodialysis. Qual Life Res. 2014;23(1):57-66.

20. Kalender B, Ozdemir AC, Dervisoglu E, Ozdemir O. Quality of life in chronic kidney disease: effects of treatment modality, depression, malnutrition and inflammation. Int J Clin Pract. 2007;61(4):569-576.

21. Kalender B, Ozdemir AC, Koroglu G. Association of depression with markers of nutrition and inflammation in chronic kidney disease and end-stage renal disease. Nephron Clin Pract. 2006;102(3-4):c115-c121.

22. Uglešić $\mathrm{B}$, Ljutić $\mathrm{D}$, Lasić $\mathrm{D}$, et al. Depression and serum interleukin-6 levels in patients on dialysis. Psychiatr Danub. 2015;27(2):168-173.

23. Hays RD, Kallich JD, Mapes DL, Coons SJ, Carter WB. Development of the kidney disease quality of life (KDQOL) instrument. Qual Life Res. 1994;3(5):329-338.

24. Picariello F, Moss-Morris R, Macdougall IC, Chilcot AJ. The role of psychological factors in fatigue among end-stage kidney disease patients: a critical review. Clin Kidney J. 2017;10(1):79-88.

25. Zalai D, Szeifert L, Novak M. Psychological distress and depression in patients with chronic kidney disease. Semin Dial. 2012;25(4):428-438.

26. De Sousa A. Psychiatric issues in renal failure and dialysis. Indian $J$ Nephrol. 2008;18(2):47-50

27. Tong A, Sainsbury P, Chadban S, et al. Patients' experiences and perspectives of living with CKD. Am J Kidney Dis. 2009;53(4):689-700.
Therapeutics and Clinical Risk Management

\section{Publish your work in this journal}

Therapeutics and Clinical Risk Management is an international, peerreviewed journal of clinical therapeutics and risk management, focusing on concise rapid reporting of clinical studies in all therapeutic areas outcomes, safety, and programs for the effective, safe, and sustained use of medicines. This journal is indexed on PubMed Central, CAS,

\section{Dovepress}

EMBase, Scopus and the Elsevier Bibliographic databases. The manuscript management system is completely online and includes a very quick and fair peer-review system, which is all easy to use. Visit $\mathrm{http}: / /$ www.dovepress.com/testimonials.php to read real quotes from published authors. 